\title{
Effects of vegetation restoration on soil quality in fragile karst ecosystems of southwest China
}

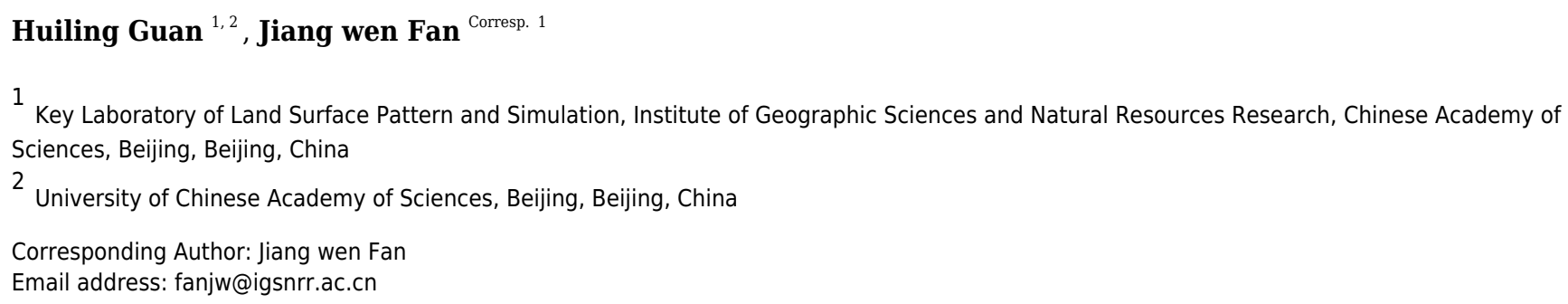

Soil quality assessment is important for karst ecosystems where soil erosion is significant.

A large amount of vegetation restoration has been implemented since the early $21^{\text {st }}$ in degraded karst areas across southwestern China. However, the impacts on soil quality of different restoration types rarely have been compared systematically. In the current study, we investigated the soil quality after a number of vegetation restoration projects as well as their adjacent cropland by analysing soil samples. Six vegetation restoration types were evaluated, including one natural restoration (natural shrubland, protected for 13 years), three economic forests (4 years Eucalyptus robusta, 4 years Prunus salicina and 6 years Zenia insignis) and two mixed forests (1 year Juglans regia-crop and 13 years Toona sinensis-Pennisetum purpureum ). We evaluated the benefits of different restoration types more accurate ly by setting each adjacent cropland as the control and setting the variation between the corresponding restored and control site as the evaluation object so that the background differences of six sites could be eliminated. The results indicated that natural shrubland, Toona sinensis-Pennisetum purpureum, and Zenia insignis were effective in improving soil quality index (SQI) in degraded karst cropland largely due to their higher SOC and TN content. The variation of SQI (VSQI) of natural shrubland was significantly higher than that in Eucalyptus robusta, Prunus salicina and Juglans regia-crop in total soil layer $(0-30 \mathrm{~cm})(P<0.05)$, indicating natural shrubland had better capacity to improve soil quality. The boosting regression tree model revealed that vegetation restoration type explained $73.49 \%$ and restoration time explained $10.30 \%$ of the variation in VSQI, which confirmed that vegetation restoration type and restoration time are critical for achieving soil reserves. Therefore, it is vital to select appropriate vegetation type in restoration projects and recovery for a long time in order to achieve better soil quality. The current study provides a theoretical basis on which to assess the effects of different vegetation restoration types on the heterogeneous degraded karst areas. 
1 Effects of vegetation restoration on soil quality in fragile karst ecosystems of southwest China

3 (1. Key Laboratory of Land Surface Pattern and Simulation, Institute of Geographic Sciences and

4 Natural Resources Research, Chinese Academy of Sciences, Beijing 100101, China; 2. University

5 of Chinese Academy of Sciences, Beijing 100049, China)

6 Corresponding author: Jiang Wen Fan

7 Abstract

8

Soil quality assessment is important for karst ecosystems where soil erosion is significant.

A large amount of vegetation restoration has been implemented since the early $21^{\text {st }}$ in degraded karst areas across southwestern China. However, the impacts on soil quality of different restoration types rarely have been compared systematically. In the current study, we investigated the soil quality after a number of vegetation restoration projects as well as their adjacent cropland by analysing soil samples. Six vegetation restoration types were evaluated, including one natural restoration (natural shrubland, protected for 13 years), three economic forests (4 years Eucalyptus robusta, 4 years Prunus salicina and 6 years Zenia insignis) and two mixed forests (1 year Juglans regia-crop and 13 years Toona sinensis-Pennisetum purpureum). We evaluated the benefits of different restoration types more accurately by setting each adjacent cropland as the control and setting the variation between the corresponding restored and control site as the evaluation object so that the background differences of six sites could be eliminated. The results indicated that

* Corresponding author

E-mail: fanjw@igsnrr.ac.cn 
natural shrubland, Toona sinensis-Pennisetum purpureum, and Zenia insignis were effective in improving soil quality index (SQI) in degraded karst cropland largely due to their higher SOC and TN content. The variation of SQI (VSQI) of natural shrubland was significantly higher than that in Eucalyptus robusta, Prunus salicina and Juglans regia-crop in total soil layer $(0-30 \mathrm{~cm})(P<$ 0.05), indicating natural shrubland had better capacity to improve soil quality. The boosting regression tree model revealed that vegetation restoration type explained $73.49 \%$ and restoration time explained $10.30 \%$ of the variation in VSQI, which confirmed that vegetation restoration type and restoration time are critical for achieving soil reserves. Therefore, it is vital to select appropriate vegetation type in restoration projects and recovery for a long time in order to achieve better soil quality. The current study provides a theoretical basis on which to assess the effects of different vegetation restoration types on the heterogeneous degraded karst areas.

Keywords: Vegetation restoration; Soil properties; Soil quality index; Karst areas

\section{Introduction}

Southwestern China has the largest continuous karst landscape in the world, spanning an area of about 510,000 $\mathrm{km}^{2}$ (Li et al. 2018c). This region is characterised by shallow soil due mainly to slow soil formation rate from limestone (Peng \& Wang 2012; Zhao et al. 2017). In addition, the steep and broken surface, the seasonal and abundant precipitation, and decades of poorly managed intensive agriculture occurring in this area all contribute toward exacerbating soil loss (Cheng et al. 2017; Peng et al. 2018; Yan et al. 2018).

To address these problems, several national-scale ecological restoration projects have been carried out in karst areas, including the Grain for Green Program, the Rocky Desertification 
41 Control Project and the Natural Forest Protection Project (Zhang et al. 2016; Zhang et al. 2018b).

42 The recovery of soil functions is vital to ecosystem regeneration of degraded croplands (Guo et al.

43 2019), many scholars have evaluated the impacts of different vegetation restoration strategies on

44 soil quality, which has been widely used to determine how soil responds to various management

practices (Raiesi \& Kabiri 2016; Guo et al. 2018; Vincent et al. 2018). However, most of these studies compared the soil quality of different vegetation restoration types without considering their original ecosystem conditions, and judged each type based only on the status quo (Yang et al. 2017; Li et al. 2018a; Zhang et al. 2019a). In fact, vegetation restoration types were taken according to different karst environments. For example, artificial grassland, shrub and forest correspond to moderate-, light- and non- karst rocky desertification, respectively (Li et al. 2009); that is to say, the environmental backgrounds of different vegetation restoration types are different. Thus, the soil quality of each vegetation restoration type cannot truly reflect its effects because factors such as topography, the degree of rocky desertification (Sheng et al. 2018) and basic soil corresponding unrestored control sites for comparison.

urgent need to compare the effects of different vegetation restoration types properly, using

In this present study, we measured soil quality parameters associated with different vegetation restoration types as well as those of corresponding adjacent unrestored croplands, and determined the difference value between the soil quality of the paired treated and untreated sites as the evaluation object. Since each paired adjacent restored and unrestored site has consistent soil parent material, climate and topographic conditions, our evaluation object could eliminate the effects of 
62 those environmental factors and only reflect the effects of vegetation restoration. Therefore, our

63 results will be able to assess the difference in effects of different vegetation types that distributed

64 in different sites on soil quality more accurately.

65 We established soil quality index (SQI) based on the Minimum Data Set (MDS) approach,

66 which is an effective and dependable method of assessing soil quality (Lin et al. 2017; Nabiollahi

67 et al. 2018). The objectives of the current study were (1) to assess the variation in soil properties

68 caused by different vegetation restoration types, (2) to calculate SQI and evaluate the effects of

69 vegetation restoration compared to cropland, (3) to calculate the variation in SQI between

70 restoration and its respective control (VSQI), in order to compare the effects of different vegetation

71 types on soil quality using the VSQI value, and (4) to identify the factors that influenced VSQI.

72 2. Materials and methods

73 2.1. Study area

74 This study was conducted in two eroded hilly karst cities, Hechi $\left(23^{\circ} 41^{\prime}-25^{\circ} 37^{\prime} \mathrm{N} ; 1^{\circ} 06^{\circ} 34^{\prime}-\right.$

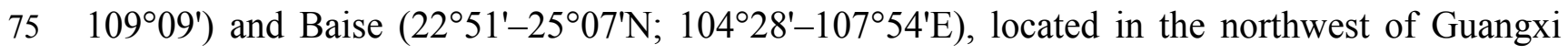

76 Province, Southwest China (Fig.1). Before 2003, the sampling sites were sloped cropland, which

77 had a serious problem of rocky desertification. From 2003, the Chinese government and

78 researchers gradually began to perform various vegetation restoration projects in this area. This

79 area is characterised by a subtropical monsoon climate, and it has an average annual temperature

80 of $18.39^{\circ} \mathrm{C}$ and an average annual rainfall of $1347.88 \mathrm{~mm}$. It can be divided into a rainy season

81 (April-August) and a dry season (October-March) each year (Li et al. 2017). Topography is high

82 in the Northwest and Southwest, but low in the South and East. The soil is dominated by calcareous 
83

lithosols over both limestone and dolomite and their mixtures (Xiao et al. 2018).

\subsection{Soil sampling and laboratory analyses}

In April 2018, six vegetation restoration types were selected for study: including one natural restoration (natural shrubland, protected for 13 years), three economic forests (4 years Eucalyptus robusta, 4 years Prunus salicina and 6 years Zenia insignis) and two mixed forests (1 year Juglans regia-crop and 13 years Toona sinensis-Pennisetum purpureum (napier grass)), they are natural shrubland, Eucalyptus robusta, Prunus salicina, Zenia insignis, Juglans regia-crop and Toona sinensis-Pennisetum purpureum for short, respectively. Three sites (Eucalyptus robusta, Prunus salicina, Juglans regia-crop) were set up in Hechi city, while the other three sites were in Baise city (Table 1). In order to ensure comparability, three $4 \mathrm{~m} \times 4 \mathrm{~m}$ plots were selected randomly and each plot is spaced more than $10 \mathrm{~m}$ apart, for assessment of each vegetation type.

Meanwhile, cropland site adjacent to each vegetation restoration site was taken as a paired control. In total, 36 plots were chosen for field observation and sampling. Before sampling, we were approved and supported by farmers and nature reserve managers of these sites. In every plot, the litter layer was removed and soil samples were collected in three replicate sub-plots from three layers $(0-10 \mathrm{~cm}, 10-20 \mathrm{~cm}$ and 20-30 cm). Samples in the same soil layer from the same subplots were mixed and sieved $(<2 \mathrm{~mm})$, removing roots and stone. A subsample of fresh soil was stored at $-20{ }^{\circ} \mathrm{C}$ for subsequent available nitrogen analyses, other subsamples were air dried, with portions sieved to $0.147 \mathrm{~mm}$.

In the laboratory, the following soil physical and chemical properties were measured according to Pang et al. (2018) and Chen et al.(2013): soil pH, soil organic carbon (SOC), total 
104

105

106

107

108

109

110

111

112

113

114

115

116

117

118

119

120

121

122

123

carbon (TC), total nitrogen (TN), total phosphorus (TP), total potassium (TK), ammoniumnitrogen $\left(\mathrm{NH}_{4}^{+}\right)$, nitrate-nitrogen $\left(\mathrm{NO}_{3}{ }^{-}\right)$, available potassium $(\mathrm{AK})$, and available phosphorus (AP).

2.3. Evaluation of the effects of vegetation restoration on soil quality index

SQI is widely used to evaluate soil quality. It consists of four procedures: 1) selection of minimum data set (MDS); 2) standardisation of each MDS parameter; 3) weighting of each MDS parameter based on a principal component analysis (PCA); and 4) calculation of SQI by merging the scores (Zhang et al. 2011).

Two steps ensure that MDS indicators are more representative and exhibit less redundancy. Firstly, PCA was performed (Doran \& Parkin 1994). We took into consideration for the MDS only those principal components (PCs) with eigenvalues $\geq 1$ (Ye et al. 2014) and which explained more than $5 \%$ of the total variation (Andrews et al. 2003). For each PC, indexes with the maximum weight and over $90 \%$ of the maximum weight were selected (Askari \& Holden 2014). Then, Pearson's correlation analysis was adopted to check whether other indicators should be removed if there were more than one high loading indicators in a single PC (Bastida et al. 2006). Wherever indicators within a PC were highly correlated with one another (correlation coefficient $>0.6$ ), we selected only the indicator with the highest eigenvector (Andrews et al. 2004).

To eliminate the differences in indicators units, a nonlinear scoring method was used to score soil indicators to a value between 0 and 1.0. The sigmoidal function (Eq. (1)) was performed as follows (Zhang et al. 2019a): 
where $i$ refers to an indicator in MDS, $S_{i}$ is the score of the $i$ soil indicator, $a$ is the maximum

126

127

128

131

132

133

134

135

136

137

138

139

140

141

142

143

144

score $(a=1), x_{i}$ is every measured value of the $i$ indicator, $x_{0 i}$ is the mean value of the $i$ soil indicator, and $b$ is the value of the equation's slope; $b=-2.5$ was applied to a 'more is better' curve and $b=2.5$ was applied to a 'less is better' curve, respectively (Bastida et al., 2006).

SQI was calculated as follows (Zhang et al. 2019a):

$$
\mathrm{SQI}=\sum_{i=1}^{n} S_{i} \times W_{i}(2)
$$

where $W_{i}$ is the weighting values of the MDS determined by PCA, $S_{i}$ is the indicator score based on Eq. (1), and $n$ is the number of the selected indicators in MDS. We assumed that higher SQI values indicated superior soil functions or better soil quality.

Variation in vegetation restoration types on soil quality index was calculated using the following equation:

$$
\mathrm{VSQI}_{j}=S Q I_{p j}-S Q I_{c k j}
$$

where $\mathrm{VSQI}_{j}$ is the changed value achieved by undertaking vegetation restoration $j, S Q I_{p j}$ is the SQI of vegetation restoration $j$, and $S Q I_{c k j}$ is the SQI of its control.

\subsection{Statistical analysis}

All data are presented as the means \pm standard error. One--way analyses of variation followed by the Tukey pairwise multiple comparison test was used to assess the differences in the soil physicochemical and SQI values among different vegetation restoration types and different soil layers at the $P<0.05$ level. Paired sample $\mathrm{t}$ test was used to evaluate the differences between restored project and adjacent unrestored cropland. PCA and Pearson's correlation analysis were 
145

146

147

used to select the soil indicators and to weight the selected indicators. Boosting regression tree model (BRT) was used to reflect the contribution of each factor and was carried out with R (R 3.50) using the gbm.step function from the dismo package in R to determine the variation in SQI that was explained by each indicator. All statistical analyses were performed by IBM SPSS 22 (IBM, Armonk, NY, USA). Figures were generated using Origin 2018b (Origin Lab., Hampton, MA, USA).

3. Results

\subsection{Effects of vegetation restoration on soil physicochemical properties}

Paired sample $t$ test evaluated the significance of vegetation restoration to soil properties, by directly comparing the result from each treated replicate plot with the corresponding adjacent untreated replicate plot (Table 2-3). Natural shrubland, Prunus salicina and Toona sinensisPennisetum purpureum had no significant effect on soil texture, while Eucalyptus robusta, Zenia insignis and Juglans regia-crop could significantly increase sand content in 0-10 cm and 10-20 $\mathrm{cm}$ soil layer, accordingly, decrease clay content $(P<0.05)$. Vegetation restoration could significantly affect $\mathrm{TN}$ content and $\mathrm{pH}(P<0.05)$, changing in opposite directions, with the exception of Toona sinensis-Pennisetum purpureum. Eucalyptus robusta could significantly decrease soil $\mathrm{pH}$, occurred in every soil layer $(P<0.05)$. Although most restoration types increased TN content significantly $(P<0.05)$, except for Prunus salicina and Juglans regia-crop, the C/N ratio still showed a significant increase under all restoration types $(P<0.01)$, except for Eucalyptus robusta. In addition, natural shrubland and Toona sinensis-Pennisetum purpureum increased SOC content significantly $(P<0.05)$, but barely increased available nutrients (AP, $\mathrm{AK}, \mathrm{NH}_{4}{ }^{+}$and $\mathrm{NO}_{3}{ }^{-}$). 
166 On the contrary, Juglans regia-crop increased AP and $\mathrm{NO}_{3}{ }^{-}$content significantly $(P<0.05)$.

167 Variation between treated restoration plot and the corresponding adjacent untreated plot can

168 be used to compare the effects of different restoration types on soil physicochemical properties.

169 Variation in sand content under Juglans regia-crop (13.37\%-21.32\%) was significantly higher than that under all other vegetation restoration types at 0-10 $\mathrm{cm}$ and $10-20 \mathrm{~cm}$ soil layers (Table 4). Silt content variation under Juglans regia-crop (10.01\%-17.19\%) was significantly lower than that for the other types at the same two soil depths, except for natural shrubland. Variation in SOC (VSOC) over the total soil depth $(0-30 \mathrm{~cm})$ was in the range $-2.56 \mathrm{~g} / \mathrm{kg}-18.10 \mathrm{~g} / \mathrm{kg}$. The VSOC under Prunus salicina was significantly lower than that under Toona sinensis-Pennisetum purpureum and natural shrubland $(P<0.05$; Fig. 2A, 2B, 2C, 2D), indicating a better SOC accumulation capacity in the latter 2 restoration types. Similarly, the variation in TN (VTN) of

Prunus salicina was significantly lower than those of all other types $(P<0.05$; Fig. 2E, 2F, 2G,

2H), except for Juglans regia-crop. In addition, significant differences in VSOC and VTN among soil depths were found only in Prunus salicina and Eucalyptus robusta, respectively, with the values decreasing with increasing soil depth $(P<0.05)$. However, no significant differences of the variation in $\mathrm{C} / \mathrm{N}$ ratio $(\mathrm{VC} / \mathrm{N})(0-30 \mathrm{~cm})$ were observed among different vegetation restoration types. The VC/N of Prunus salicina and natural shrubland increased significantly with greater soil depth $(P<0.05$; Fig. 2I, 2J, 2K, 2L).

According to the variation in $\mathrm{pH}(0-30 \mathrm{~cm})(\mathrm{VpH})$, the vegetation restoration types can be divided into three categories: 1) $\mathrm{VpH}$ was positive (0.73-0.90), including Prunus salicina, Juglans 
187 188

-0.29), including natural shrubland and Zenia insignis; and 3) $\mathrm{pH}$ was greatly reduced $(-2.53)$, including only one restoration type (Eucalyptus robusta). Significant differences were found among the three categories $(P<0.05$; Fig. $2 \mathrm{M}, 2 \mathrm{~N}, 2 \mathrm{O}, 2 \mathrm{P})$. The significant difference of $\mathrm{VpH}$ in response to greater soil depth was found only in Eucalyptus robusta, under which VpH decreased with greater soil depth $(P<0.05)$.

Variation in TP (VTP) $(0-30 \mathrm{~cm})$ was in the range $-1.29 \mathrm{~g} / \mathrm{kg}-0.18 \mathrm{~g} / \mathrm{kg}$, natural shrubland was the only vegetation restoration type with a positive VTP, which was significantly higher than all other five types $(P<0.05$; Fig. 2T). VTP in Zenia insignis was significantly lower than those for the other types at $0-10 \mathrm{~cm}$ and 10-20 cm soil depth $(P<0.05$; Fig. 2Q, 2R), indicating that TP decreased greatly under Zenia insignis. The absolute value of VTP for Prunus salicina and Zenia insignis decreasing significantly with greater soil depth $(P<0.05$; Fig. 2Q, 2R, 2S). Variation in TK (VTK) under Juglans regia-crop was significantly lower than that under the other restoration types, followed by Prunus salicina $(P<0.05$; Fig. 2U, 2V, 2W, 2X). Variation in AP (VAP) (0$30 \mathrm{~cm}$ ) was in the range $-15.82 \mathrm{mg} / \mathrm{kg}-3.52 \mathrm{mg} / \mathrm{kg}$. The VAP values under Toona sinensisPennisetum purpureum, natural shrubland and Zenia insignis were significantly lower than those under Juglans regia-crop and Eucalyptus robusta $(P<0.05$; Fig. 2BB). The absolute value of VAP decreased with greater soil depth, with significant differences among the various soil depths being observed under natural shrubland, Zenia insignis and Prunus salicina $(P<0.05$; Fig. 2Y, 2Z, 2AA). No significant differences were observed among restoration types at the deepest soil layer $(20-30 \mathrm{~cm})$. Prunus salicina was the only restoration type with positive variation in AK (VAK) (0-30 cm), being significantly higher than that under Zenia insignis, Juglans regia-crop 
208

209

210

211

212

213

214

215

216

217

218

219

220

221

222

223

224

225

226

227

228

and Toona sinensis-Pennisetum purpureum $(P<0.05$; Fig. 2FF). Similar to VAP, the absolute value of VAK had a tendency to decrease with soil depth, with the exception of Eucalyptus robusta (Fig. 2CC, 2DD, 2EE) and the absolute value of variation in $\mathrm{NO}_{3}{ }^{-}\left(\mathrm{VNO}_{3}{ }^{-}\right)(0-30 \mathrm{~cm})$ decreased significantly with soil depth, except for Zenia insignis and Juglans regia-crop $(P<0.05$; Fig. 2GG, 2HH, 2II). Variation in $\mathrm{NH}_{4}^{+}\left(\mathrm{VNH}_{4}^{+}\right)(0-30 \mathrm{~cm})$ was between $-2.28 \mathrm{mg} / \mathrm{kg}$ and $7.84 \mathrm{mg} / \mathrm{kg}(\mathrm{Fig}$. 2NN). The $\mathrm{VNH}_{4}^{+}$values under Eucalyptus robusta was the largest and was significantly higher than that under restorations except Zenia insignis $(P<0.05)$.

\subsection{Evaluation of soil quality index}

PCA based on all measured values, showed that the five main PCs with eigenvalues $>1$ explained $81.35 \%$ of the total variation (Table 5). The major weighted indicators were SOC, TP, TK and $\mathrm{AP}$ in $\mathrm{PC} 1$, sand was the only suitable indicator in $\mathrm{PC} 2, \mathrm{TN}$ and $\mathrm{NO}_{3}{ }^{-}$were selected for PC3, AK and $\mathrm{pH}$ were selected for PC4, and clay was selected for PC5. Significant correlation > $0.6(P<0.05)$ was observed between AP and TP in PC1, and AP was removed (Table 6). Thus, the precise MDS contained nine indicators: TN, SOC, TP, TK, $\mathrm{AK}, \mathrm{pH}, \mathrm{NO}_{3}{ }^{-}$, clay and sand. The weighting values were analysed by PCA based on the MDS measured values (Table 7). Then, SQI was calculated by Eq (4):

$\mathrm{SQI}=(0.16 \times \mathrm{TN})+(0.21 \times \mathrm{SOC})+(0.14 \times \mathrm{TP})+(0.06 \times \mathrm{TK})+(0.13 \times \mathrm{AK})+(0.08 \times \mathrm{pH})+$ $\left(0.05 \times \mathrm{NO}_{3}^{-}\right)+(0.09 \times$ clay $)+(0.08 \times$ sand $)(4)$

Natural shrubland, Toona sinensis-Pennisetum purpureum and Zenia insignis increased SQI significantly $(P<0.01)$ comparing to the cropland at $0-30 \mathrm{~cm}$ soil layer, with increasing value $0.17,0.17$ and 0.10 , respectively. Furthermore, natural shrubland had significant higher SQI at all 
229

230

231

232

three soil layers, while Prunus salicina only improve SQI at $10-20 \mathrm{~cm}$ soil layer $(P<0.05)$ (Table 8). Variation in SQI (VSQI) of natural shrubland in total soil depth $(0-30 \mathrm{~cm})$ was highest and significantly higher than that of Eucalyptus robusta, Prunus salicina and Juglans regia-crop, while Juglans regia-crop with lowest VSQI at every soil layer significantly lower than that of natural shrubland and Toona sinensis-Pennisetum purpureum (Fig.3) $(P<0.05)$. Significant difference of VSQI among soil depth only found in Eucalyptus robusta, which decreased with increasing soil depth $(P<0.05)$.

In the BRT model, vegetation restoration type, restoration time (year), surface vegetation coverage, soil depth, latitude, longitude, elevation and slope of the study site were considered for analysing the variation in VSQI (Fig.4). Vegetation restoration type explained the largest proportion of VSQI variation (73.49\%), followed by restoration time (10.30\%), soil depth (7.74\%), and latitude (5.31\%), with the other four factors having little effect on VSQI.

4. Discussion

\subsection{The effects of vegetation restoration on soil quality compared to cropland}

The effects of vegetation restoration on soil quality in degraded lands remain controversial.

Some studies reported that vegetation restoration could improve soil physicochemical properties in karst cropland, such as increasing soil nutrients like SOC, N concentration (Chen et al. 2019; Liu et al. 2019; Zhang et al. 2019a); others supported that most of the restoration projects were failed or get limited success (Asmelash et al. 2016), especially in the fragile karst ecosystem southwest China, where an ecological 'tipping point' may have been passed, beyond which soil properties are unrecoverable in manageable timescales (Guo et al. 2019). In our study, none of the 
250

vegetation restoration types decreased soil quality significantly, with VSQI between $\square 0.03$ and 0.17, SQI values in natural shrubland, Toona sinensis-Pennisetum purpureum and Zenia insignis in total soil depth $(0-30 \mathrm{~cm})$ were significantly higher than that in the corresponding controls (Table 8). This may be due to that Toona sinensis-Pennisetum purpureum and natural shrubland all significantly increased SOC and TN compared to cropland (Table 3), and Zenia insignis also achieved a non-negligible increase in SOC and TN (Fig.2), which were the dominant indicators to developing SQI in this study. Our findings are in accordance with the previous results that levels of SOC and TN in natural restoration vegetation (Chen et al. 2012; Wang et al. 2018) and combination of plantation trees and forage grasses (Xiao et al. 2017a; Hu et al. 2019) were significantly higher than the corresponding values in cropland due to greater litter input in these restoration types. On the other hand, SOC in the cropland decomposed rapidly as a result of land cultivation (Zhu et al. 2014), which leads to more severe reduction in subtropical karst area (Jiang et al. 2006). No significant increase of SOC were found in the remaining vegetation restorations, probably because tree species in these restorations were fast-growing and not conducive to the accumulation of SOC. In addition, Eucalyptus robusta and Juglans regia-crop, significantly increase sand content that weaken soil quality (Table 2), similar to the previous studies showed that sand content in woodlands was higher than that in adjacent cropland (Qin et al. 2017; Xiao et al. 2017b). Moreover, the restoration time of Juglans regia-crop (1 year) was too short to make significant accumulation of soil organic matter. Thus, no significant improve of SQI were observed in these 2 restorations compared to cropland.

VSQI in Eucalyptus robusta decreased with increasing soil depth $(P<0.05)$, which consistent 
271

272

273

274

275

276

277

278

279

280

281

282

283

284

285

286

with previous studies that soil quality was higher in surface soil layer than that in the deeper layers, due to the litter accumulating on the surface and then transformed into nutrients with microbial activity (Mukhopadhyay et al. 2016; Zhang et al. 2019a). However, we found that the improvement of soil quality in subsoil was better than that of surface soil in natural shrubland, Toona sinensis-Pennisetum purpureum and Prunus salicina (Table 8), mainly due to the variation in $\mathrm{NO}_{3}{ }^{-}$and $\mathrm{AK}$ increased with increasing soil depth in these restoration types (Fig.2CC-2JJ), as a result of the surface soil of cropland being nutrient-rich from application of inorganic fertilisers. On the other hand, the subsoil of unplowed soil has a considerable capacity to adsorb P and K, resulting in increasing concentrations of these nutrients in subsoil (Zhang et al. 2013; Roy \& Bickerton 2014), and resulting in lower reductions or even increases in nutrient concentrations in subsoil of restorations when comparing to cropland. Over all, this study demonstrated that natural shrubland, Toona sinensis-Pennisetum purpureum and Zenia insignis could improve soil quality in degraded karst cropland, while Prunus salicina only make efficiency in subsoil.

\subsection{Analysis of the effects of different vegetation restoration types on soil quality}

Previous studies confirmed that the ability of different vegetation restoration types to improve soil quality are different (Yu et al. 2018; Dang et al. 2020; Liu et al. 2020). In this study, the effect on soil quality $(0-30 \mathrm{~cm})$ of natural shrubland was significantly higher than that of Eucalyptus robusta, Prunus salicina and Juglans regia-crop(Fig.3), mainly due to the significant higher of variation of SOC, TN, TP and TK in natural shrubland (Fig 2D, 2H, 2T and 2X). The benefits of vegetation restoration evaluated by the value of the difference between vegetation restoration and the corresponding farmland has similar results to those of direct value responses, recent relevant 
292 studies, such as Yang et al. (2017) reported that SOC and TN in natural reserve were higher than

293 that in economic forests (Zenia insignis, Toona sinensis and orchard); Tang et al. (2015) found

294 that natural successional plant communities had higher soil fertility parameters, such as SOC, AN,

295 AP and AK, as compared with Pinus plantations; Pang et al. (2019) proved that forest natural

regeneration was more effective on SOC sequestration than Pinus and Eucalyptus plantation.

These findings can be explained by the fact that less human disturbance and higher soil nutrients

input supplied by dead wood and leaf litter in natural recovery community (Li et al. 2018b; Shen

et al. 2020). In contrast, Eucalyptus robusta, Prunus salicina and Juglans regia-crop have limited

influence on soil improvement mainly resulted by their fast growing and high output that would

accelerate absorption of soil nutrients (Laclau et al. 2005; Zhang et al. 2015; Macdonald et al.

2019). Furthermore, plantation of Eucalyptus robusta greatly reduced soil $\mathrm{pH}$, this acidifying

effect was also reported by lots of studies (Rhoades \& Binkley 1996; Soumare et al. 2016; Zhang

et al. 2019b), which may subsequently cause soil nutrient deficiency (Banfield et al. 2018),

supported by our result that $\mathrm{pH}$ was positively correlated with most nutrient contents (Table.6).

Variation in soil quality was affected by many factors, but only eight main factors were

considered in this study. The result of boosting regression tree model showed that restoration type

had the greatest contribution (73.49\%) to the final VSQI, which was in accordance with previous

studies that vegetation type is the key factor affecting soil quality (Fan et al. 2019; Yan et al, 2020).

Therefore, the selection of the most appropriate restoration type for vegetation restoration in karst

areas is crucial in terms of effectively improving soil quality. Followed by restoration time

312 (10.30\%), soil depth (7.74\%), and latitude (5.31\%), together contributing to $96.84 \%$ of VSQI 
313 variation. Similarly, Zhang et al. (2019a) found that restoration type and soil depth were the two

314 most important factors contributing to SQI of vegetation restoration in degraded karst areas. In

315 addition, restoration time played a non-negligible role in VSQI, due mainly to ecosystem carbon

316 stock sequestration achieved over time as a result of vegetation restoration (Zhang et al. 2018a),

317 since soil organic matter/carbon is the key factor to determining soil quality (Bunemann et al.

318 2018). In conclusion, vegetation restoration type is the dominant factor that affects soil quality and

319 the longer restoration time achieves the better restoration effects. Thus, natural shrubland has better

capacity to recover soil quality than Eucalyptus robusta, Prunus salicina and Juglans regia-crop

321 in karst regions.

322

5 Conclusions

323

Effect of vegetation restoration on soil quality was evaluated by the soil quality index, and

the benefits of different vegetation restoration types were compared by the value of the difference

between vegetation restoration and the corresponding cropland (VSQI). In summary, restoration

type accounted for the most variation $(73.49 \%)$ of the VSQI, and then restoration time $(10.30 \%)$,

soil depth (7.74\%), it is of great significance to select suitable vegetation types and last for a long

time for restoration to improve soil quality. Natural shrubland had better capacity in improving

soil quality in degraded karst cropland than Eucalyptus robusta, Prunus salicina and Juglans

regia-crop, mainly due to its higher SOC and TN content. Among them, natural shrubland and

Toona sinensis-Pennisetum purpureum were the most effective restoration type for degraded

cropland. Further research should examine the impacts of soil biological properties in soil quality

index and take the structure and composition of each vegetation community into consideration. 
334 Funding

335 This work was supported by the National Key Research and Development Program 336 (2017YFC0506505).

337 References

338 Andrews, S.S., Flora, C.B., Mitchell, J.P. \& Karlen, D.L. (2003). Growers' perceptions and acceptance of soil quality indices. Geoderma, 114, 187-213.

Andrews, S.S., Karlen, D.L. \& Cambardella, C.A. (2004). The soil management assessment framework: A quantitative soil quality evaluation method. Soil Sci. Soc. Am. J., 68, 19451962.

Askari, M.S. \& Holden, N.M. (2014). Indices for quantitative evaluation of soil quality under grassland management. Geoderma, 230, 131-142.

Asmelash, F., Bekele, T. \& Birhane, E. (2016). The Potential Role of Arbuscular Mycorrhizal Fungi in the Restoration of Degraded Lands. Frontiers in Microbiology, 7.

Banfield, C.C., Braun, A.C., Barra, R., Castillo, A. \& Vogt, J. (2018). Erosion proxies in an exotic tree plantation question the appropriate land use in Central Chile. Catena, 161, 77-84.

Bastida, F., Moreno, J.L., Hernandez, T. \& Garcia, C. (2006). Microbiological degradation index of soils in a semiarid climate. Soil Biology \& Biochemistry, 38, 3463-3473.

Bunemann, E.K., Bongiorno, G., Bai, Z.G., Creamer, R.E., De Deyn, G., de Goede, R., Fleskens, L., Geissen, V., Kuyper, T.W., Mader, P., Pulleman, M., Sukkel, W., van Groenigen, J.W. \& Brussaard, L. (2018). Soil quality - A critical review. Soil Biology \& Biochemistry, 120, $105-125$. 
355 Chen, F.L., Zheng, H., Zhang, K., Ouyang, Z.Y., Wu, Y.F., Shi, Q. \& Li, H.L. (2013). Non-linear

356 impacts of Eucalyptus plantation stand age on soil microbial metabolic diversity. Journal

357 of Soils and Sediments, 13, 887-894.

358 Chen, H., Zheng, M., Mao, Q., Xiao, K., Wang, K. \& Li, D. (2019). Cropland conversion changes

359 the status of microbial resource limitation in degraded karst soil. Geoderma, 352, 197-203.

360 Chen, H.S., Zhang, W., Wang, K.L. \& Hou, Y. (2012). Soil organic carbon and total nitrogen as

361 affected by land use types in karst and non-karst areas of northwest Guangxi, China. J. Sci.

$362 \quad$ Food Agric., 92, 1086-1093.

363 Cheng, F., Lu, H.F., Ren, H., Zhou, L., Zhang, L.H., Li, J., Lu, X.J., Huang, D.W. \& Zhao, D. (2017). Integrated emergy and economic evaluation of three typical rocky desertification control modes in karst areas of Guizhou Province, China. J. Clean Prod., 161, 1104-1128.

Dang, Z.Q., Huang, Z., Tian, F.P., Liu, Y., Lopez-Vicente, M. \& Wu, G.L. (2020). Five-year soil

Doran, J.W. \& Parkin, T.B. (1994). DEFINING AND ASSESSING SOIL QUALITY. In: Defining

Soil Quality for a Sustainable Environment (eds. Doran, JW, Coleman, DC, Bezdicek, DF

\& Stewart, BA). Soil Science Soc Amer Madison, pp. 3-21.

Fan, Z.Z., Lu, S.Y., Liu, S., Guo, H., Wang, T., Zhou, J.X. \& Peng, X.W. (2019). Changes in Plant Rhizosphere Microbial Communities under Different Vegetation Restoration Patterns in Karst and Non-karst Ecosystems. Scientific Reports, 9, 12.

375 Guo, S.J., Han, X.H., Li, H., Wang, T., Tong, X.G., Ren, G.X., Feng, Y.Z. \& Yang, G.H. (2018). 
Evaluation of soil quality along two revegetation chronosequences on the Loess Hilly Region of China. Science of the Total Environment, 633, 808-815.

378 Guo, Z., Zhang, X., Green, S.M., Dungait, J.A.J., Wen, X. \& Quine, T.A. (2019). Soil enzyme activity and stoichiometry along a gradient of vegetation restoration at the Karst Critical Zone Observatory in Southwest China. Land Degradation \& Development, 30, 1916-1927.

Hu, P.L., Zhang, W., Xiao, L.M., Yang, R., Xiao, D., Zhao, J., Wang, W.L., Chen, H.S. \& Wang, K.L. (2019). Moss-dominated biological soil crusts modulate soil nitrogen following

Jiang, Y.J., Yuan, D.X., Zhang, C., Kuang, M.S., Wang, J.L., Xie, S.Y., Li, L.L., Zhang, G. \& He, R.S. (2006). Impact of land-use change on soil properties in a typical karst agricultural region of Southwest China: a case study of Xiaojiang watershed, Yunnan. Environmental Geology, 50, 911-918.

Karlen, D.L., Ditzler, C.A. \& Andrews, S.S. (2003). Soil quality: why and how? Geoderma, 114, $145-156$.

Laclau, J.P., Ranger, J., Deleporte, P., Nouvellon, Y., Saint-Andre, L., Marlet, S. \& Bouillet, J.P. (2005). Nutrient cycling in a clonal stand of Eucalyptus and an adjacent savanna ecosystem in Congo 3. Input-output budgets and consequences for the sustainability of the plantations. Forest Ecology and Management, 210, 375-391.

Li, D.J., Wen, L., Jiang, S., Song, T.Q. \& Wang, K.L. (2018a). Responses of soil nutrients and microbial communities to three restoration strategies in a karst area, southwest China. Journal of Environmental Management, 207, 456-464. 
397

398

399

400

401

402

403

404

405

406

407

408

409

410

411

412

413

414

415

416

417

Li, D.J., Yang, Y., Chen, H., Xiao, K.C., Song, T.Q. \& Wang, K.L. (2017). Soil Gross Nitrogen

Transformations in Typical Karst and Nonkarst Forests, Southwest China. Journal of Geophysical Research-Biogeosciences, 122, 2831-2840.

Li, R.R., Kan, S.S., Zhu, M.K., Chen, J., Ai, X.Y., Chen, Z.Q., Zhang, J.J. \& Ai, Y.W. (2018b).

Effect of different vegetation restoration types on fundamental parameters, structural characteristics and the soil quality index of artificial soil. Soil \& Tillage Research, 184, 11-23.

Li, Y.B., Shao, J.A., Yang, H. \& Bai, X.Y. (2009). The relations between land use and karst rocky desertification in a typical karst area, China. Environmental Geology, 57, 621-627.

Li, Z.W., Xu, X.L., Xu, C.H., Liu, M.X. \& Wang, K.L. (2018c). Dam construction impacts on multiscale characterization of sediment discharge in two typical karst watersheds of southwest China. Journal of Hydrology, 558, 42-54.

Lin, Y.M., Deng, H.J., Du, K., Li, J., Lin, H., Chen, C., Fisher, L., Wu, C.Z., Hong, T. \& Zhang, G.S. (2017). Soil quality assessment in different climate zones of China's Wenchuan earthquake affected region. Soil \& Tillage Research, 165, 315-324.

Liu, X., Zhang, W., Wu, M., Ye, Y.Y., Wang, K.L. \& Li, D.J. (2019). Changes in soil nitrogen stocks following vegetation restoration in a typical karst catchment. Land Degradation \& Development, 30, 60-72.

Liu, Y.L., Zhu, G.Y., Hai, X.Y., Li, J.W., Shangguan, Z.P., Peng, C.H. \& Deng, L. (2020). Longterm forest succession improves plant diversity and soil quality but not significantly increase soil microbial diversity: Evidence from the Loess Plateau. Ecological 
419

420

421

422

423

424

425

426

427

428

429

430

431

432

433

434

435

436

437

438

Macdonald, S., Bailey, T., Hunt, M., Davidson, N. \& Jordan, G. (2019). Stable states in soil chemistry persist in eucalypt woodland restorations. Appl. Veg. Sci., 22, 105-114.

Mukhopadhyay, S., Masto, R.E., Yadav, A., George, J., Ram, L.C. \& Shukla, S.P. (2016). Soil quality index for evaluation of reclaimed coal mine spoil. Science of the Total Environment, 542, 540-550.

Nabiollahi, K., Golmohamadi, F., Taghizadeh-Mehrjardi, R., Kerry, R. \& Davari, M. (2018). Assessing the effects of slope gradient and land use change on soil quality degradation through digital mapping of soil quality indices and soil loss rate. Geoderma, 318, 16-28.

Pang, D.B., Cao, J.H., Dan, X.Q., Guan, Y.H., Peng, X.W., Cui, M., Wu, X.Q. \& Zhou, J.X. (2018). Recovery approach affects soil quality in fragile karst ecosystems of southwest China: Implications for vegetation restoration. Ecological Engineering, 123, 151-160.

Pang, D.B., Cui, M., Liu, Y.G., Wang, G.Z., Cao, J.H., Wang, X.R., Dan, X.Q. \& Zhou, J.X. (2019). Responses of soil labile organic carbon fractions and stocks to different vegetation restoration strategies in degraded karst ecosystems of southwest China. Ecological Engineering, 138, 391-402.

Peng, T. \& Wang, S.J. (2012). Effects of land use, land cover and rainfall regimes on the surface runoff and soil loss on karst slopes in southwest China. Catena, 90, 53-62.

Peng, X.D., Dai, Q.H., Li, C.L. \& Zhao, L.S. (2018). Role of underground fissure flow in nearsurface rainfall-runoff process on a rock mantled slope in the karst rocky desertification area. Eng. Geol., 243, 10-17. 
439 Qin, Y.B., Xin, Z.B., Wang, D.M. \& Xiao, Y.L. (2017). Soil organic carbon storage and its 440 influencing factors in the riparian woodlands of a Chinese karst area. Catena, 153, 21-29.

441 Raiesi, F. \& Kabiri, V. (2016). Identification of soil quality indicators for assessing the effect of 442 Ecological Indicators, 71, 198-207. and Albizia plantations. Forest Ecology and Management, 80, 47-56.

Vincent, Q., Auclerc, A., Beguiristain, T.\& Leyval, C. (2018). Assessment of derelict soil quality: 
Abiotic, biotic and functional approaches. Science of the Total Environment, 613, 9901002.

Wang, M.M., Chen, H.S., Zhang, W. \& Wang, K.L. (2018). Soil nutrients and stoichiometric ratios as affected by land use and lithology at county scale in a karst area, southwest China. Science of the Total Environment, 619, 1299-1307.

Xiao, K.C., He, T.G., Chen, H., Peng, W.X., Song, T.Q., Wang, K.L. \& Li, D.J. (2017a). Impacts of vegetation restoration strategies on soil organic carbon and nitrogen dynamics in a karst area, southwest China. Ecological Engineering, 101, 247-254.

Xiao, K.C., Li, D.J., Wen, L., Yang, L.Q., Luo, P., Chen, H. \& Wang, K.L. (2018). Dynamics of soil nitrogen availability during post-agricultural succession in a karst region, southwest China. Geoderma, 314, 184-189.

Xiao, W., Feng, S.Z., Liu, Z.F., Su, Y.R., Zhang, Y. \& He, X.Y. (2017b). Interactions of soil particulate organic matter chemistry and microbial community composition mediating carbon mineralization in karst soils. Soil Biology \& Biochemistry, 107, 85-93.

Yan, Y.J., Dai, Q.H., Yuan, Y.F., Peng, X.D., Zhao, L.S. \& Yang, J. (2018). Effects of rainfall Geoderma, 330, 30-40. regions of SW China. Science of The Total Environment, 136543. 50.

Yang, J., Xu, X.L., Liu, M.X., Xu, C.H., Zhang, Y.H., Luo, W., Zhang, R.F., Li, X.Z., Kiely, G. 
\& Wang, K.L. (2017). Effects of "Grain for Green" program on soil hydrologic functions in karst landscapes, southwestern China. Agric. Ecosyst. Environ., 247, 120-129.

Ye, C., Cheng, X.L. \& Zhang, Q.F. (2014). Recovery approach affects soil quality in the water level fluctuation zone of the Three Gorges Reservoir, China: implications for revegetation. Environmental Science and Pollution Research, 21, 2018-2031.

Yu, P.J., Liu, S.W., Zhang, L., Li, Q. \& Zhou, D.W. (2018). Selecting the minimum data set and quantitative soil quality indexing of alkaline soils under different land uses in northeastern China. Science of the Total Environment, 616, 564-571.

Zhang, C., Xue, S., Liu, G.B. \& Song, Z.L. (2011). A comparison of soil qualities of different revegetation types in the Loess Plateau, China. Plant and Soil, 347, 163-178.

Zhang, H., Duan, H.B., Song, M.W. \& Guan, D.S. (2018a). The dynamics of carbon accumulation in Eucalyptus and Acacia plantations in the Pearl River delta region. Ann. For. Sci., 75, 13.

Zhang, J.Y., Dai, M.H., Wang, L.C. \& Su, W.C. (2016). Household livelihood change under the rocky desertification control project in karst areas, Southwest China. Land Use Policy, 56, 8-15.

Zhang, K., Zheng, H., Chen, F.L., Ouyang, Z.Y., Wang, Y., Wu, Y.F., Lan, J., Fu, M. \& Xiang, X.W. (2015). Changes in soil quality after converting Pinus to Eucalyptus plantations in southern China. Solid Earth, 6, 115-123.

Zhang, M.Y., Wang, K.L., Liu, H.Y., Zhang, C.H., Yue, Y.M. \& Qi, X.K. (2018b). Effect of ecological engineering projects on ecosystem services in a karst region: A case study of northwest Guangxi, China. J. Clean Prod., 183, 831-842. 
502 Zhang, S.L., Zhang, X.Y., Liu, X.B., Liu, W. \& Liu, Z.H. (2013). Spatial distribution of soil 503 nutrient at depth in black soil of Northeast China: a case study of soil available potassium. $504 \quad$ Nutr. Cycl. Agroecosyst., 95, 319-331.

505 Zhang, Y.H., Xu, X.L., Li, Z.W., Liu, M.X., Xu, C.H., Zhang, R.F. \& Luo, W. (2019a). Effects of 506 vegetation restoration on soil quality in degraded karst landscapes of southwest China. 507 Science of the Total Environment, 650, 2657-2665.

508 Zhang, Y.S., Zheng, X.Z., Ren, X.Y., Zhang, J.B., Misselbrook, T., Cardenas, L., Carswell, A., 509 Muller, C. \& Ding, H. (2019b). Land-use type affects nitrate production and consumption 510 pathways in subtropical acidic soils. Geoderma, 337, 22-31.

511 Zhao, Y.J., Li, Z., Zhang, J., Song, H.Y., Liang, Q.H., Tao, J.P., Cornelissen, J.H.C. \& Liu, J.C. 512 (2017). Do shallow soil, low water availability, or their combination increase the 513 competition between grasses with different root systems in karst soil? Environmental $514 \quad$ Science and Pollution Research, 24, 10640-10651.

515 Zhu, B., Gutknecht, J.L.M., Herman, D.J., Keck, D.C., Firestone, M.K. \& Cheng, W.X. (2014).

516 Rhizosphere priming effects on soil carbon and nitrogen mineralization. Soil Biology \& 517 Biochemistry, 76, 183-192. 
Figure 1

Location of study sites.

From the easternmost counterclockwise point are Eucalyptus robusta economic forest, Juglans regia-crop mixed forest, Prunus salicina economic forest, Toona sinensis-Pennisetum purpureum mixed forest, natural shrubland and Zenia insignis economic forest, respectively. My data: Resource and Environment Data Cloud Platform ( http://www.resdc.cn/ )

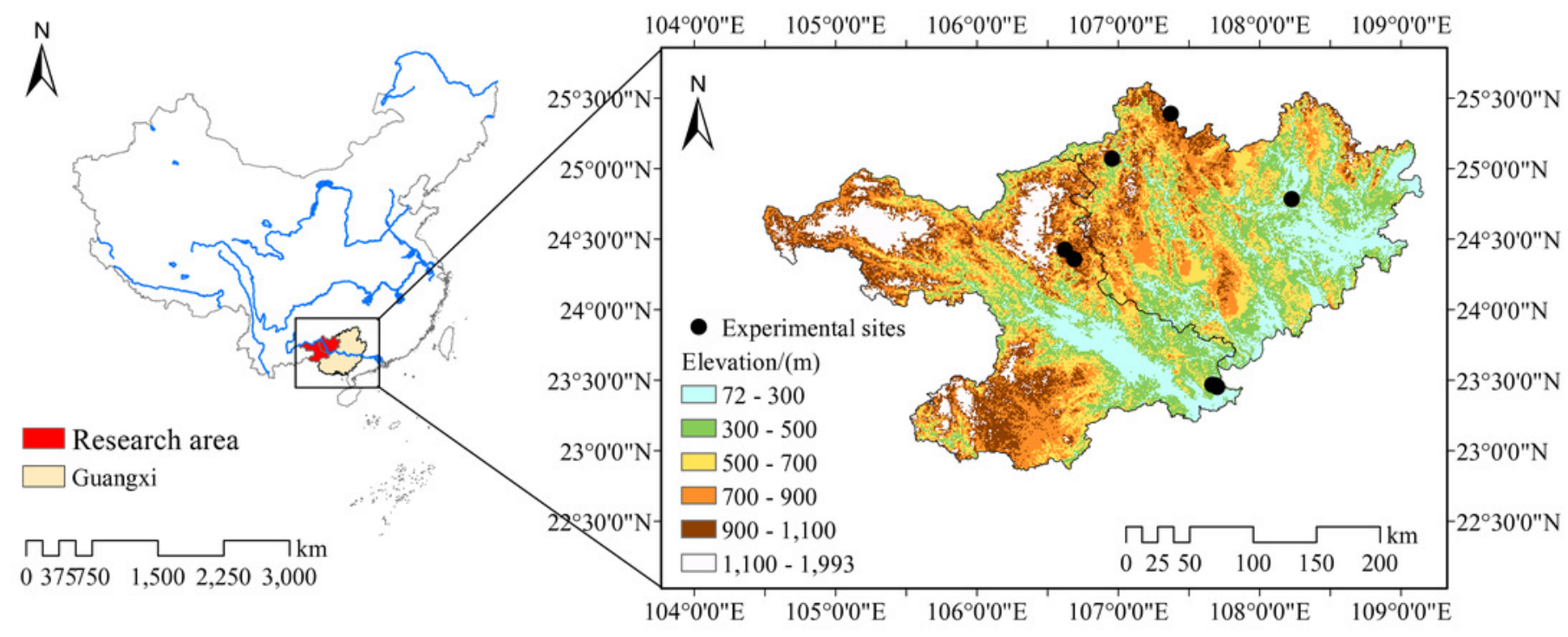




\section{Figure 2 (on next page)}

Variation in soil physicochemical indicators under different types.

NS $(n=3)$, natural shrubland; EF $(n=4)$, Eucalyptus robusta economic forest; PF $(n=3)$, Prunus salicina economic forest; $Z F(n=3)$, Zenia insignis economic forest; JC $(n=3)$, Juglans regiacrop mixed forest; TG $(n=3)$, Toona sinensis- Pennisetum purpureum mixed forest. Data were obtained from three soil layers $(0-10 \mathrm{~cm}, 10-20 \mathrm{~cm}$ and $20-30 \mathrm{~cm})$ and their averages $(0-30$ $\mathrm{cm})$. From $A$ to $N N$, are soil organic carbon (SOC), total nitrogen (TN), the ratio of SOC to TN $(\mathrm{C} / \mathrm{N}), \mathrm{pH}$, total phosphorus (TP), total potassium (TK), available phosphorus (AP); available potassium (AK); nitrate-nitrogen $\left(\mathrm{NO}_{3}^{-}\right)$and ammonium-nitrogen $\left(\mathrm{NH}_{4}^{+}\right)$in 4 layers, respectively. Error bars correspond to standard deviation. Green column indicates positive variation, and orange column indicates negative variation. Different lowercase letters indicate significant difference among different vegetation restoration types at the same depth (one-way ANOVA, $P<0.05$ ) and different uppercase letters indicate significant difference under different soil depths at the same type (one-way ANOVA, $P<0.05$ ). The same below. 


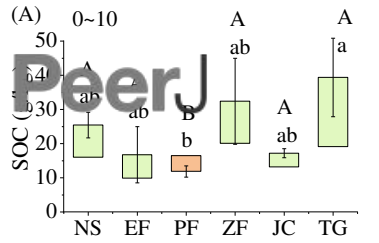

(C) $20 \sim 30$

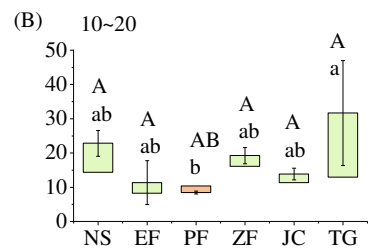

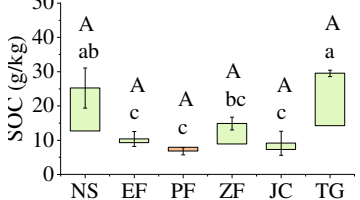

(D) $\quad 0 \sim 30$

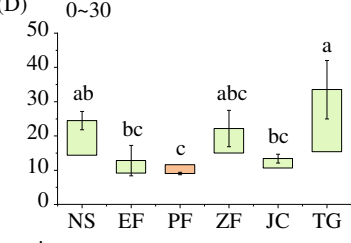
Vegetation restoration types
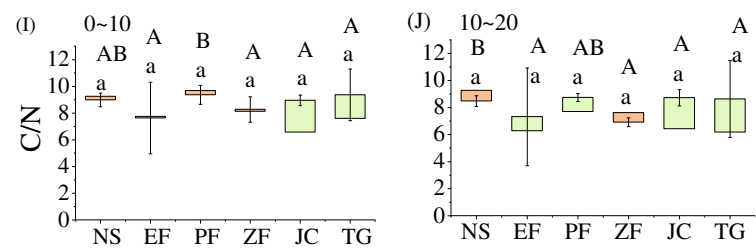

(K) $\quad 20 \sim 30$

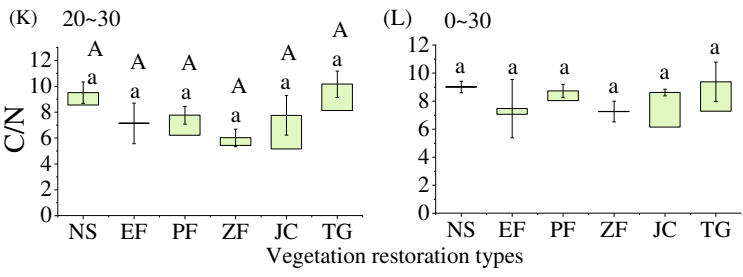

(Q) $\quad 0 \sim 10$

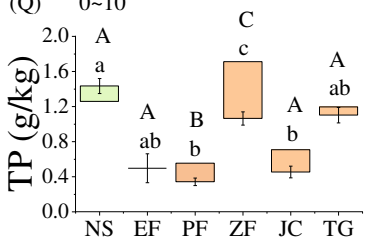

(R) $\quad 10 \sim 20$

$\left.\begin{array}{l}2.0 \\ 1.6\end{array}\right] \mathrm{A}$

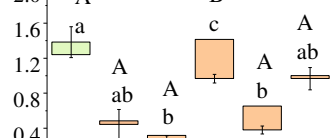

$\begin{array}{llll}0.4 & \mathrm{~b} \\ 0.0 & \mathrm{NS} & \mathrm{EF} & \mathrm{PF}\end{array}$

(S) $20 \sim 30$

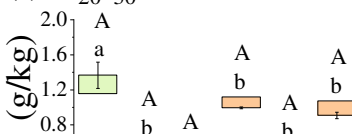

(T) $0 \sim 30$

2.0
1.6
1.2
0.8 ${ }^{\mathrm{a}} \mathrm{b}_{\mathrm{bc}}^{\mathrm{b}}$

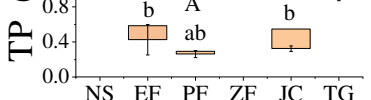

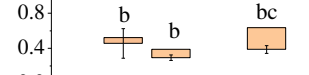

$\begin{array}{llllll}0.0 & & & & & \\ \text { NS } & \text { EF } & \text { PF } & \text { ZF } & \text { JC } & \text { TG }\end{array}$ Vegetation restoration types

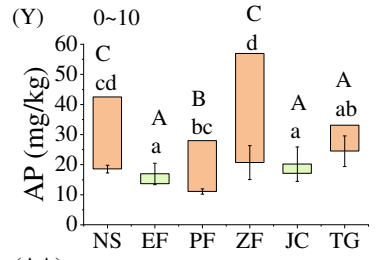

(Z) $60 \quad 10 \sim 20$

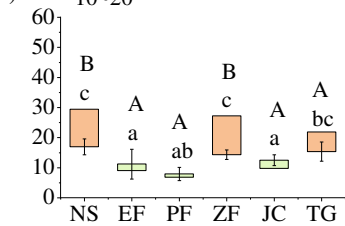

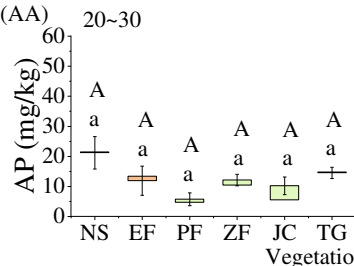

(BB) $0 \sim 30$

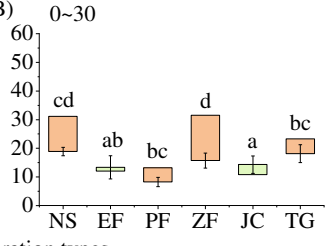

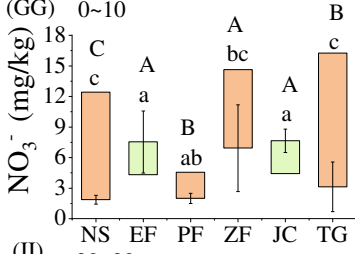

(II) 18 20

每 $12 . \mathrm{A} \quad \mathrm{AB} \quad \mathrm{A}$

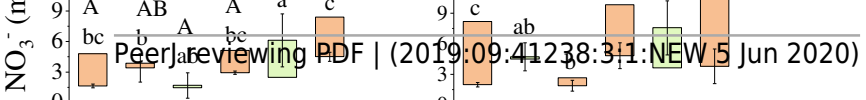

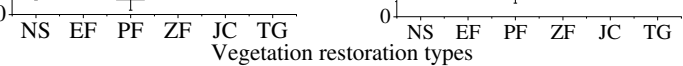

(E) $\begin{array}{llll}0 \sim 10 & \mathrm{~A} & \mathrm{~A} & \text { (F) }{ }_{5} 10 \sim 20\end{array}$

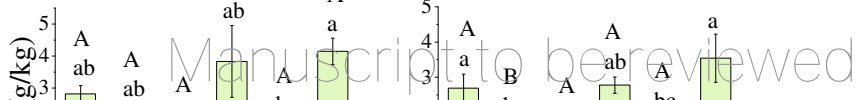

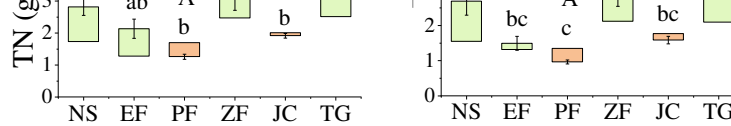

(G) $20 \sim 30$

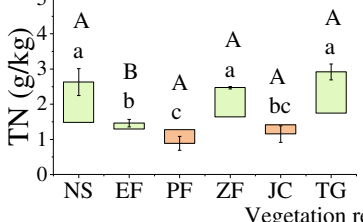

(H) $\quad 0 \sim 30$

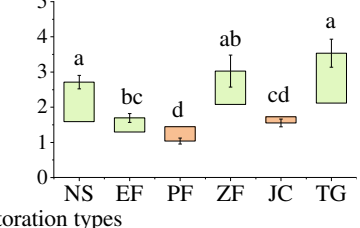

(M) $\quad 0 \sim 10$

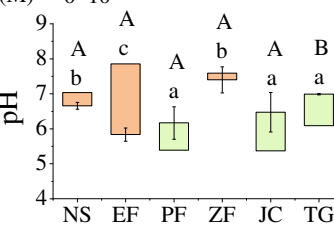

(O) ${ }_{9}^{20 \sim 30}{ }_{\mathrm{B}}$

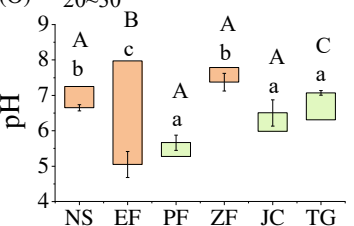

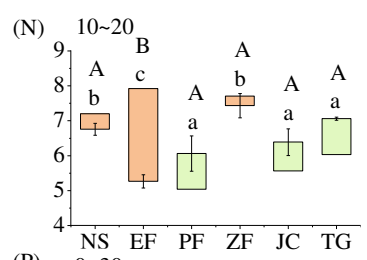

(P) $\quad 0 \sim 30$

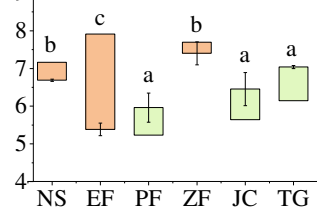

Vegetation restoration types
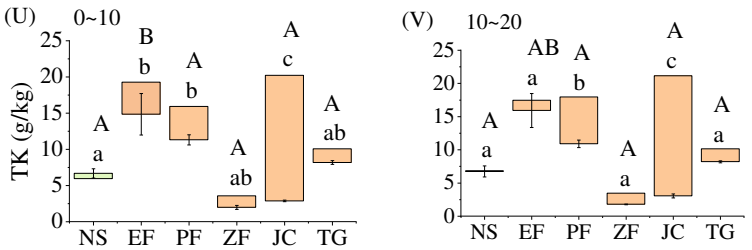

(W) $\quad 20 \sim 30$

(X) $\quad 0 \sim 30$
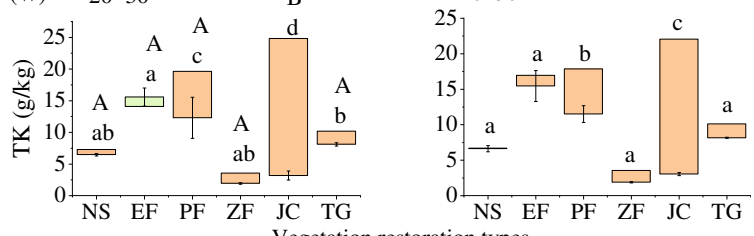

Vegetation restoration types

(CC) ${ }_{150} 0 \sim 10 \quad \mathrm{~A} \quad \mathrm{~A} \quad \mathrm{~A} \quad \mathrm{~B} \quad$ (DD) $15010 \sim 20$

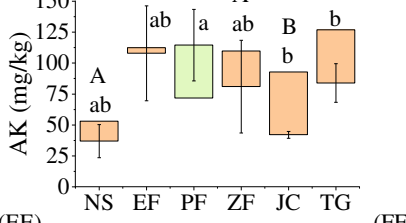

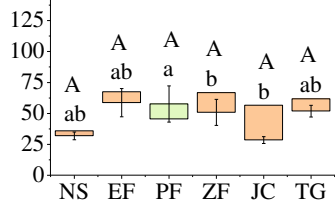

(EE) $150{ }^{20 \sim 30}$

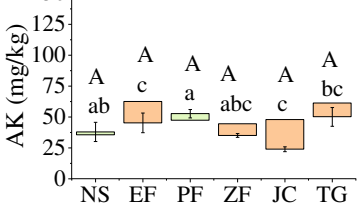

(FF) ${ }_{150}, 0 \sim 30$

125 .

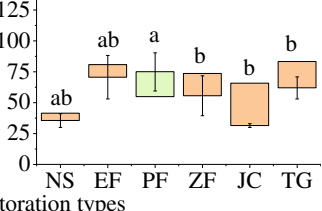

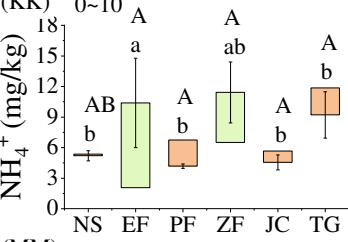

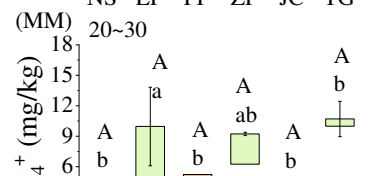

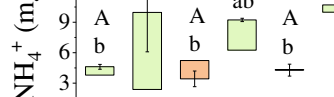

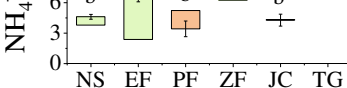

(LL) $10 \sim 20$

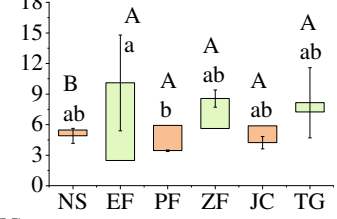

(NN) ${ }_{18} 0 \sim 30$

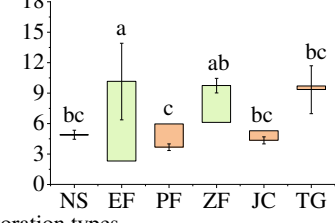


Figure 3

Variation in soil quality index under different restoration types

VSQI: variation in soil quality index.
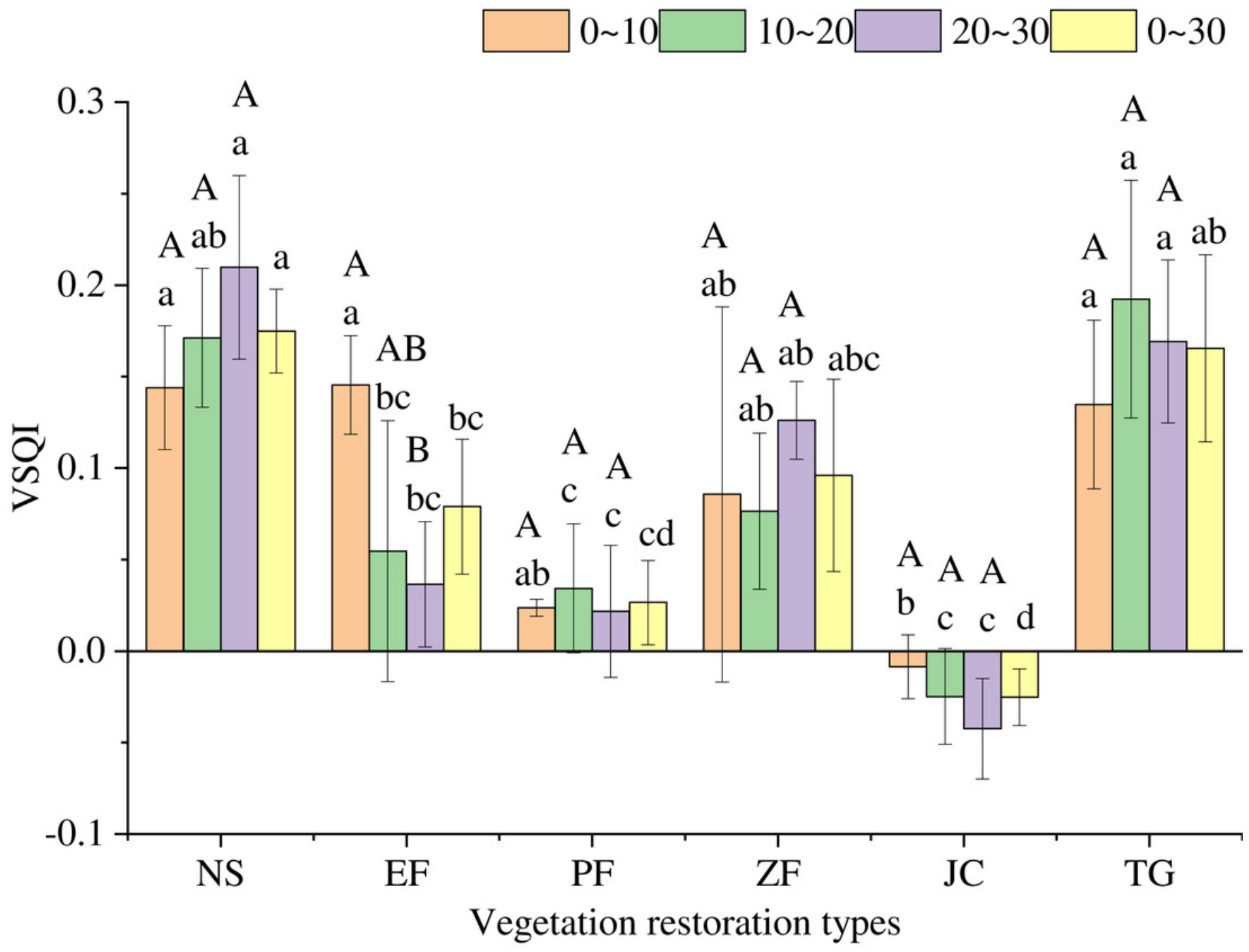


\section{Figure 4}

Effects on the variation soil quality index by the boosting regression tree model

Results obtained from boosting regression tree model (BRT) showed the integrative effects of vegetation restoration type, soil depth, restoration time, latitude, longitude, elevation, coverage and slope on the variance soil quality index.

vegetation restoration type

restoration time

- soil depth

latitude

- longitude

- coverage

- elevation

- slope

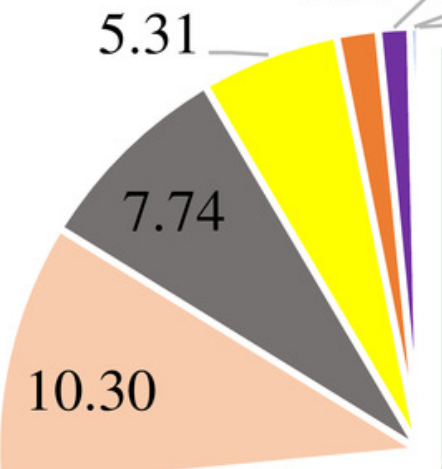

$1.21 \quad 0.32$

73.49 


\section{Table $\mathbf{1}$ (on next page)}

Basic profiles of experimental plots 
1 Table 1 Basic profiles of experimental plots

\begin{tabular}{|c|c|c|c|c|c|c|}
\hline $\begin{array}{l}\text { Vegetation } \\
\text { restoration } \\
\text { types }\end{array}$ & Natural shrubland & Eucalyptus robusta & Prunus salicina & $\begin{array}{l}\text { Zenia } \\
\text { insignis }\end{array}$ & $\begin{array}{l}\text { Juglans } \\
\text { regia-crop }\end{array}$ & $\begin{array}{c}\text { Toona sinensis- } \\
\text { Pennisetum purpureum }\end{array}$ \\
\hline Study sites & Baise & Hechi & Hechi & Baise & Hechi & Baise \\
\hline Area/ha & 13 & 20 & 26.7 & 6.7 & 20 & 13.3 \\
\hline $\begin{array}{l}\text { Elevation/ } \\
\qquad \mathrm{m}\end{array}$ & 653 & 243 & 488 & 229 & 846 & 740 \\
\hline Slope/ ${ }^{\circ}$ & 15 & 20 & 15 & 30 & 20 & 25 \\
\hline $\begin{array}{l}\text { Mean tree } \\
\text { height } / \mathrm{m}\end{array}$ & 2.1 & 10 & 2.5 & 8 & 2.3 & 12 \\
\hline $\begin{array}{l}\text { Vegetation } \\
\text { cover } \%\end{array}$ & 70 & 60 & 50 & 70 & 20 & 20 \\
\hline $\begin{array}{l}\text { Before } \\
\text { restoration }\end{array}$ & cropland & cropland & cropland & $\begin{array}{l}\text { croplan } \\
\text { d }\end{array}$ & cropland & cropland \\
\hline $\begin{array}{l}\text { Recovery } \\
\text { time/year }\end{array}$ & 13 & 4 & 4 & 6 & 1 & 13 \\
\hline
\end{tabular}




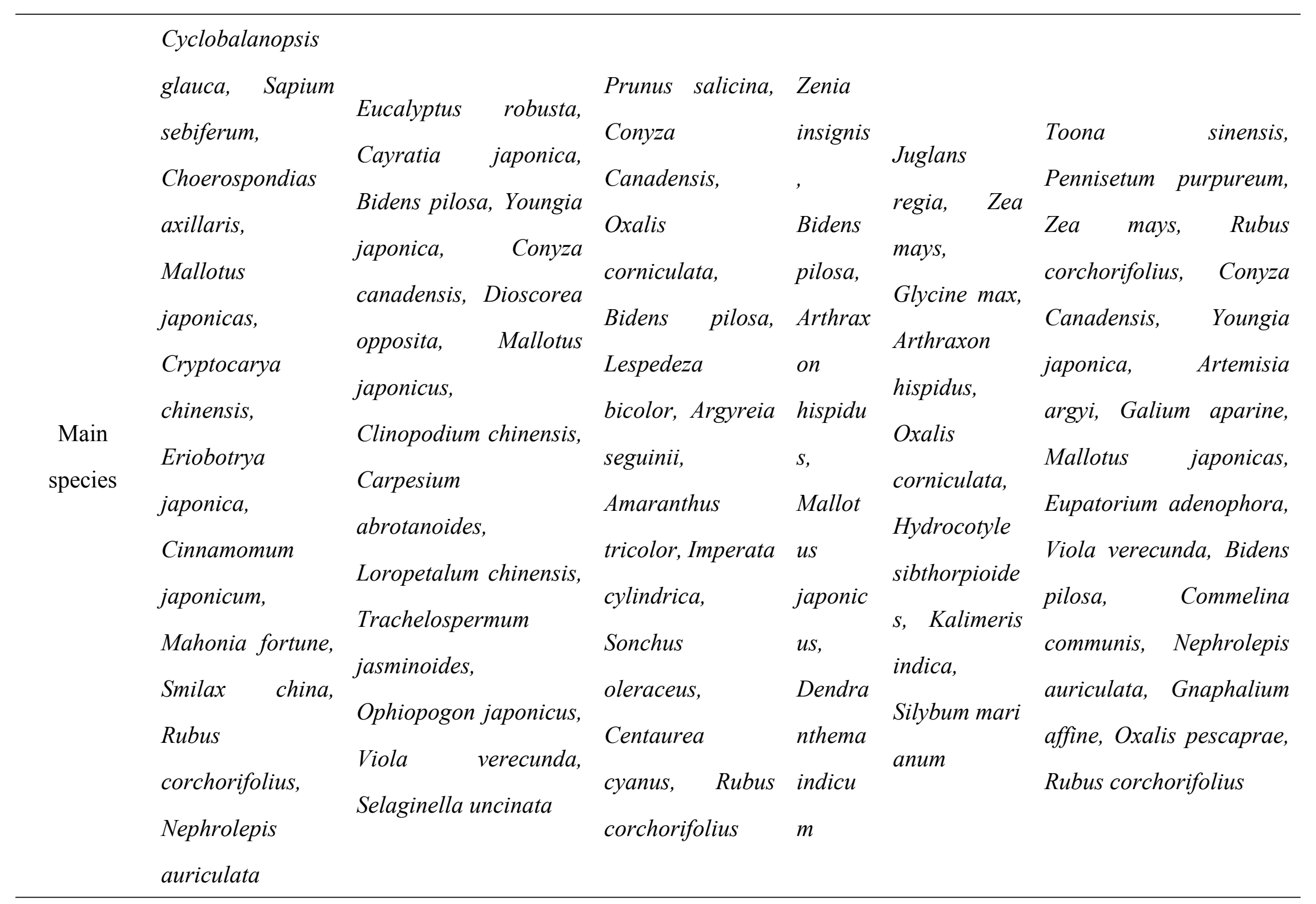




\section{Table 2 (on next page)}

Paired t test values for effect on soil texture (clay, silt, sand) between vegetation restoration type and the control 
1 Table 2 Paired t test values for effect on soil texture (clay, silt, sand) between vegetation

2 restoration type and the control

\begin{tabular}{|c|c|c|c|c|c|}
\hline Set & Soil texture & $0-30 \mathrm{~cm}$ & $0-10 \mathrm{~cm}$ & $10-20 \mathrm{~cm}$ & $20-30 \mathrm{~cm}$ \\
\hline \multirow{4}{*}{$\mathrm{NS}-\mathrm{CK} 1$} & Clay & & & & \\
\hline & Silt & & & & \\
\hline & Sand & & & & \\
\hline & Clay & - & - & - & \\
\hline \multirow[t]{3}{*}{$\mathrm{EF}-\mathrm{CK} 2$} & Silt & + & ++ & + & \\
\hline & Sand & + & & & \\
\hline & Clay & & & & \\
\hline \multirow[t]{3}{*}{$\mathrm{PF}-\mathrm{CK} 3$} & Silt & & & & \\
\hline & Sand & & & & \\
\hline & Clay & -- & - & - & - \\
\hline \multirow[t]{3}{*}{$\mathrm{ZF}-\mathrm{CK} 4$} & Silt & ++ & + & + & + \\
\hline & Sand & ++ & + & + & \\
\hline & Clay & -- & -- & - & \\
\hline \multirow[t]{3}{*}{$\mathrm{JC}-\mathrm{CK} 5$} & Silt & -- & -- & - & - \\
\hline & Sand & ++ & ++ & + & \\
\hline & Clay & & & & \\
\hline TG - CK6 & Silt & & & & \\
\hline
\end{tabular}


Sand

3 Note: ++ or --: Difference is significant at $P<0.01$ level in double-tailed t test. +or- :

4 Difference is significant at $P<0.05$ level in double-tailed t test. + indicates a significant increase

5 and - indicates a significant decrease, empty shows no significant change. NS, natural shrubland;

6 EF, Eucalyptus robusta economic forest; PF, Prunus salicina economic forest; ZF, Zenia insignis

7 economic forest; JC, Juglans regia-crop mixed forest; TG, Toona sinensis-Pennisetum purpureum

8 mixed forest. $\mathrm{n}=3$ in every soil layer, $\mathrm{n}=9$ in total soil layer $(0-30 \mathrm{~cm})$ for 6 restoration types except

9 for $E F$, which $n=4$ in every soil layer and $n=12$ in total soil layer $(0-30 \mathrm{~cm})$. The same below. 


\section{Table 3(on next page)}

Paired t test values for effect on soil indicators between vegetation restoration type and the control 
1 Table 3 Paired t test values for effect on soil indicators between vegetation restoration type and the control

\begin{tabular}{|c|c|c|c|c|c|c|c|c|c|c|c|}
\hline Set & Soil layer & SOC & $\mathrm{TN}$ & $\mathrm{TP}$ & TK & $\mathrm{AP}$ & $\mathrm{AK}$ & $\mathrm{NH}_{4}{ }^{+}$ & $\mathrm{NO}_{3}{ }^{-}$ & $\mathrm{C} / \mathrm{N}$ & $\mathrm{pH}$ \\
\hline \multirow[t]{4}{*}{$\mathrm{NS}-\mathrm{CK} 1$} & $0-30$ & ++ & ++ & ++ & & - & & & -- & ++ & -- \\
\hline & $0-10$ & & + & ++ & & -- & & & - & & \\
\hline & $10-20$ & & + & & & - & & & - & & - \\
\hline & $20-30$ & & + & & & & & & - & & \\
\hline \multirow[t]{4}{*}{$\mathrm{EF}-\mathrm{CK} 2$} & $0-30$ & & ++ & & & & & + & & & -- \\
\hline & $0-10$ & & + & & & & & + & & & -- \\
\hline & $10-20$ & & & & & & & + & - & & -- \\
\hline & $20-30$ & & + & & & & - & + & & & -- \\
\hline \multirow[t]{4}{*}{$\mathrm{PF}-\mathrm{CK} 3$} & $0-30$ & & -- & & -- & & + & -- & & ++ & ++ \\
\hline & $0-10$ & & & & - & & & & & & \\
\hline & $10-20$ & & - & & -- & & & & & & \\
\hline & $20-30$ & & - & - & & & & - & & & \\
\hline
\end{tabular}




\begin{tabular}{|c|c|c|c|c|c|c|c|c|c|c|c|}
\hline \multirow[t]{4}{*}{$\mathrm{ZF}-\mathrm{CK} 4$} & $0-30$ & & ++ & -- & -- & - & & ++ & & ++ & -- \\
\hline & $0-10$ & & & - & - & - & & & & & \\
\hline & $10-20$ & & + & -- & -- & - & - & + & & & \\
\hline & $20-30$ & & ++ & & -- & & & ++ & & & \\
\hline \multirow[t]{4}{*}{$\mathrm{JC}-\mathrm{CK} 5$} & $0-30$ & & - & -- & -- & + & -- & - & ++ & ++ & ++ \\
\hline & $0-10$ & & & - & -- & & & & & & \\
\hline & $10-20$ & & & -- & -- & & & -- & & & + \\
\hline & $20-30$ & & & & - & ++ & - & & & + & \\
\hline \multirow[t]{4}{*}{ TG - CK6 } & $0-30$ & ++ & ++ & & -- & & & & -- & ++ & ++ \\
\hline & $0-10$ & & + & & - & & & - & & & \\
\hline & $10-20$ & & + & & & & & & & & + \\
\hline & $20-30$ & & + & & -- & & - & & - & & + \\
\hline
\end{tabular}

2 Note: SOC: soil organic carbon, TN: total nitrogen, C/N: the ratio of SOC to TN, TP: total phosphorus, TK: total potassium, AP:

3 available phosphorus, $\mathrm{AK}$ : available potassium, $\mathrm{NH}_{4}^{+}$: ammonium-nitrogen, $\mathrm{NO}_{3}^{-}$: nitrate-nitrogen. 


\section{Table 4 (on next page)}

Soil texture (clay, silt, sand) analysis for variation in different vegetation restoration types 
1 Table 4 Soil texture (clay, silt, sand) analysis for variation in different vegetation restoration 2 types

\begin{tabular}{|c|c|c|c|c|}
\hline Types & Depth & Clay $(\%)$ & Silt (\%) & Sand $(\%)$ \\
\hline \multirow{3}{*}{ NS } & $0-10 \mathrm{~cm}$ & $2.01 \pm 0.56 \mathrm{Aa}$ & $-1.69 \pm 0.58 \mathrm{Ab}$ & $-0.33 \pm 0.26 \mathrm{Ab}$ \\
\hline & $10-20 \mathrm{~cm}$ & $2.35 \pm 1.03 \mathrm{Aa}$ & $-2.07 \pm 1.61 \mathrm{Abc}$ & $-0.28 \pm 0.68 \mathrm{Ab}$ \\
\hline & $20-30 \mathrm{~cm}$ & $1.89 \pm 0.36 \mathrm{Aa}$ & $-1.84 \pm 0.41 \mathrm{Aab}$ & $-0.05 \pm 0.20 \mathrm{Ab}$ \\
\hline \multirow{3}{*}{$\mathrm{EF}$} & $0-10 \mathrm{~cm}$ & $-4.63 \pm 1.76 \mathrm{Ac}$ & $4.53 \pm 1.40 \mathrm{Aa}$ & $0.10 \pm 0.48 \mathrm{Ab}$ \\
\hline & $10-20 \mathrm{~cm}$ & $-5.72 \pm 3.46 \mathrm{Ac}$ & $4.28 \pm 2.51 \mathrm{Aa}$ & $1.45 \pm 0.97 \mathrm{Ab}$ \\
\hline & $20-30 \mathrm{~cm}$ & $0.83 \pm 2.44 \mathrm{Aa}$ & $-1.38 \pm 2.78 \mathrm{Bab}$ & $0.55 \pm 1.06 \mathrm{Ab}$ \\
\hline \multirow{3}{*}{$\mathrm{PF}$} & $0-10 \mathrm{~cm}$ & $-0.38 \pm 3.11 \mathrm{Bab}$ & $-0.12 \pm 1.79 \mathrm{Ab}$ & $0.50 \pm 1.35 \mathrm{Ab}$ \\
\hline & $10-20 \mathrm{~cm}$ & $-1.68 \pm 2.65 \mathrm{Babc}$ & $1.30 \pm 2.04 \mathrm{Aab}$ & $0.39 \pm 0.61 \mathrm{Ab}$ \\
\hline & $20-30 \mathrm{~cm}$ & $-3.17 \pm 1.77 \mathrm{Aab}$ & $2.50 \pm 1.43 \mathrm{Aa}$ & $0.67 \pm 0.34 \mathrm{Aab}$ \\
\hline \multirow{3}{*}{$\mathrm{ZF}$} & $0-10 \mathrm{~cm}$ & $-5.85 \pm 1.12 \mathrm{Ac}$ & $4.70 \pm 0.91 \mathrm{Aa}$ & $1.15 \pm 0.21 \mathrm{Ab}$ \\
\hline & $10-20 \mathrm{~cm}$ & $-5.89 \pm 0.85 \mathrm{Ac}$ & $4.81 \pm 0.68 \mathrm{Aa}$ & $1.08 \pm 0.17 \mathrm{Ab}$ \\
\hline & $20-30 \mathrm{~cm}$ & $-5.17 \pm 0.71 \mathrm{Ab}$ & $4.02 \pm 0.72 \mathrm{Aa}$ & $1.15 \pm 0.14 \mathrm{Aab}$ \\
\hline \multirow{3}{*}{$\mathrm{JC}$} & $0-10 \mathrm{~cm}$ & $-4.13 \pm 0.54 \mathrm{Abc}$ & $4.70 \pm 2.10 \mathrm{Ac}$ & $21.32 \pm 2.10 \mathrm{Aa}$ \\
\hline & $10-20 \mathrm{~cm}$ & $-4.44 \pm 2.17 \mathrm{Abc}$ & $4.81 \pm 1.92 \mathrm{Ac}$ & $20.68 \pm 4.08 \mathrm{Aa}$ \\
\hline & $20-30 \mathrm{~cm}$ & $-3.35 \pm 2.60 \mathrm{Aab}$ & $4.02 \pm 4.40 \mathrm{Ab}$ & $13.37 \pm 5.27 \mathrm{Aa}$ \\
\hline \multirow{3}{*}{$\mathrm{TG}$} & $0-10 \mathrm{~cm}$ & $-4.04 \pm 0.98 \mathrm{Abc}$ & $1.26 \pm 1.81 \mathrm{Aab}$ & $2.78 \pm 2.25 \mathrm{Ab}$ \\
\hline & & & & \\
\hline & $10-20 \mathrm{~cm}$ & $0.92 \pm 1.91 \mathrm{Aab}$ & $-0.65 \pm 1.50 \mathrm{Ab}$ & $-0.26 \pm 0.42 \mathrm{Ab}$ \\
\hline
\end{tabular}


$20-30 \mathrm{~cm}-1.51 \pm 3.16 \mathrm{Aab}-4.85 \pm 7.88 \mathrm{Aab} \quad 6.36 \pm 11.03 \mathrm{Aab}$

3 Note: NS $(\mathrm{n}=3)$, natural shrubland; EF $(\mathrm{n}=4)$, Eucalyptus robusta economic forest; PF $(\mathrm{n}=3)$,

4 Prunus salicina economic forest; ZF (n=3), Zenia insignis economic forest; JC (n=3), Juglans

5 regia-crop mixed forest; TG (n=3), Toona sinensis-Pennisetum purpureum mixed forest. Different

6 lowercase letters indicate significant difference among different vegetation restoration types at the

7 same depth (one-way ANOVA, $P<0.05$ ) and different uppercase letters indicate significant

8 difference under different soil depths at the same type (one-way ANOVA, $P<0.05$ ). The same

9 below. 


\section{Table 5 (on next page)}

Principal components analysis of soil properties 
Table 5 Principal components analysis of soil properties

\begin{tabular}{|c|c|c|c|c|c|}
\hline Principal component & $\mathrm{PC}-1$ & $\mathrm{PC}-2$ & $\mathrm{PC}-3$ & $\mathrm{PC}-4$ & $\mathrm{PC}-5$ \\
\hline Eigenvalues & 3.59 & 2.63 & 1.76 & 1.52 & 1.07 \\
\hline Variation (\%) & 27.65 & 20.24 & 13.57 & 11.66 & 8.23 \\
\hline Cumulative (\%) & 27.65 & 47.89 & 61.46 & 73.12 & 81.35 \\
\hline $\mathrm{TN}$ & 0.49 & -0.32 & 0.72 & 0.11 & -0.13 \\
\hline $\mathrm{SOC}$ & 0.78 & -0.06 & 0.50 & 0.20 & 0.12 \\
\hline $\mathrm{C} / \mathrm{N}$ & 0.51 & -0.27 & 0.18 & 0.30 & 0.48 \\
\hline $\mathrm{TP}$ & 0.77 & 0.33 & -0.08 & -0.37 & 0.10 \\
\hline TK & -0.72 & 0.41 & 0.11 & 0.32 & 0.13 \\
\hline AP & 0.71 & 0.33 & -0.42 & 0.07 & 0.11 \\
\hline $\mathrm{AK}$ & 0.22 & 0.56 & -0.10 & 0.51 & -0.17 \\
\hline $\mathrm{pH}$ & 0.68 & -0.10 & -0.13 & -0.53 & -0.08 \\
\hline $\mathrm{NH}_{4}^{+}$ & 0.32 & 0.35 & 0.31 & 0.46 & -0.48 \\
\hline $\mathrm{NO}_{3}^{-}$ & 0.49 & 0.21 & -0.65 & 0.27 & -0.28 \\
\hline clay & 0.04 & 0.62 & 0.00 & 0.14 & 0.58 \\
\hline silt & -0.11 & 0.64 & 0.37 & -0.45 & -0.28 \\
\hline sand & 0.07 & -0.88 & -0.31 & 0.29 & -0.10 \\
\hline
\end{tabular}

2 Notes: PC-1, PC-2, PC-3, PC -4 and $\mathrm{PC}-5$ indicate the first to fifth principal component,

3 respectively. Bold factors are considered highly weighted; TN indicates total nitrogen; SOC

4 indicates soil organic carbon; $\mathrm{C} / \mathrm{N}$ indicates the ratio of SOC to TN; TP indicates total phosphorus; 
5 TK indicates total potassium; AP indicates available phosphorus; AK indicates available

6 potassium; $\mathrm{NH}_{4}{ }^{+}$indicates ammonium-nitrogen and $\mathrm{NO}_{3}{ }^{-}$indicates nitrate-nitrogen. 
Table 6(on next page)

Pearson correlation coefficients of soil properties 
Table 6 Pearson correlation coefficients of soil properties

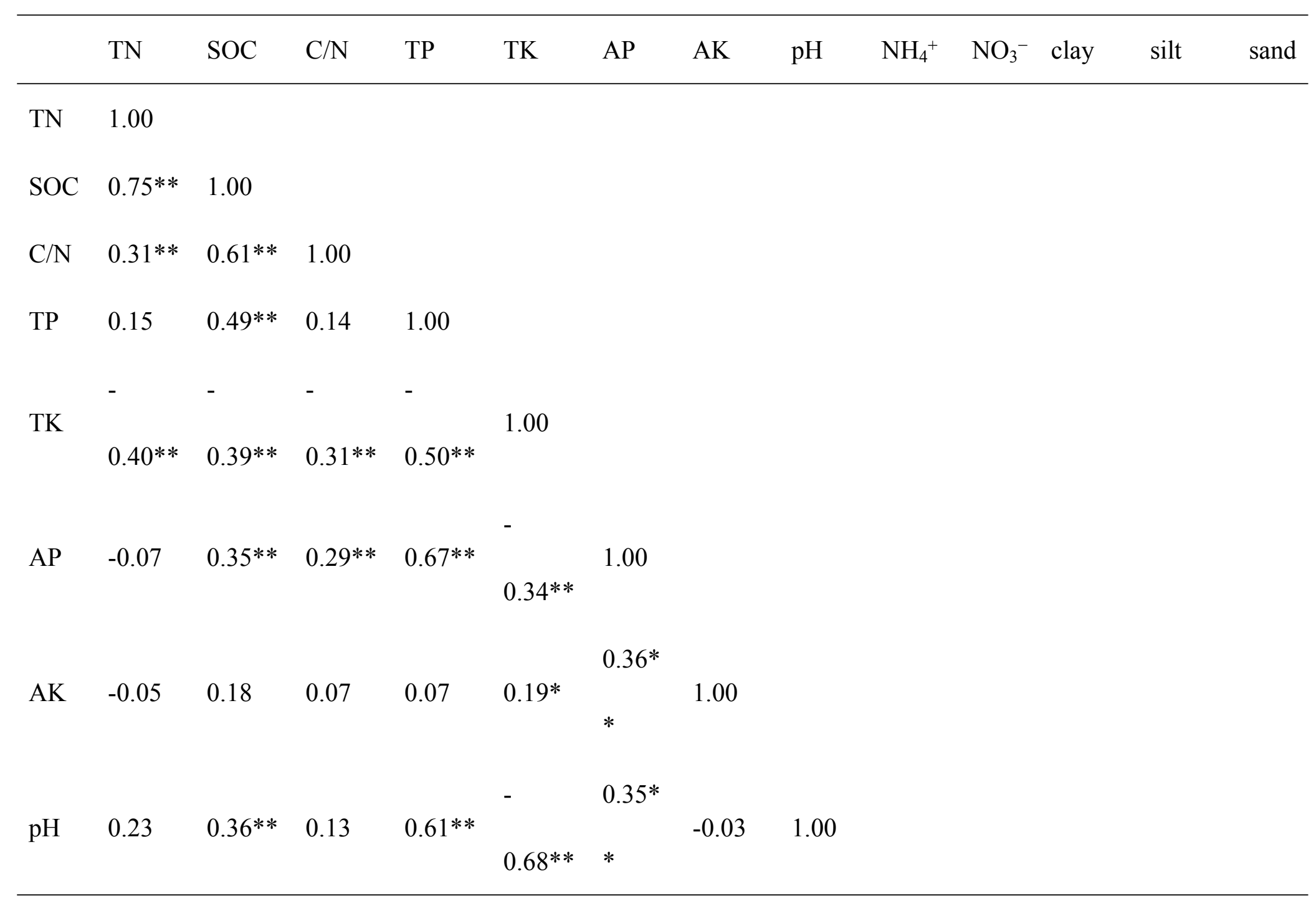




\begin{tabular}{|c|c|c|c|c|c|c|c|c|c|c|c|c|c|}
\hline $\mathrm{NH}_{4}^{+}$ & $0.34 * *$ & $0.35^{* *}$ & -0.03 & 0.18 & -0.02 & 0.17 & $0.34 * *$ & -0.08 & 1.00 & & & & \\
\hline $\mathrm{NO}_{3}{ }^{-}$ & $-0.22 *$ & 0.10 & 0.06 & $0.34 * *$ & $\begin{array}{l}- \\
0.28 * *\end{array}$ & $\begin{array}{l}0.61 * \\
*\end{array}$ & $0.40 * *$ & $\begin{array}{l}0.27 * \\
*\end{array}$ & $\begin{array}{l}0.26^{*} \\
*\end{array}$ & 1.00 & & & \\
\hline clay & -0.15 & 0.04 & -0.03 & $0.26^{* *}$ & $0.27 * *$ & $0.20 *$ & $0.24 *$ & -0.08 & 0.15 & 0.04 & 1.00 & & \\
\hline silt & -0.08 & -0.04 & $-0.22 *$ & 0.17 & $0.22 *$ & -0.03 & 0.17 & 0.02 & 0.12 & -0.17 & -0.01 & 1.00 & \\
\hline sand & 0.15 & 0.01 & $0.20 *$ & $\begin{array}{l}- \\
0.29 * *\end{array}$ & $\begin{array}{l}- \\
0.33^{* *}\end{array}$ & -0.09 & $\begin{array}{l}- \\
0.28 * *\end{array}$ & 0.03 & -0.18 & 0.12 & $\begin{array}{l}- \\
0.56^{* *}\end{array}$ & $\begin{array}{l}- \\
0.82 * *\end{array}$ & 1.00 \\
\hline
\end{tabular}

2 Note: ${ }^{*}$ Correlation is significant at $P<0.01$ level.

$3 *$ Correlation is significant at $P<0.05$ level. 
Table 7 (on next page)

Normalization equation of scoring curves 
Table 7 Normalization equation of scoring curves

\begin{tabular}{lccccccccc}
\hline Parameter & $\mathrm{TN}$ & $\mathrm{SOC}$ & $\mathrm{TP}$ & $\mathrm{TK}$ & $\mathrm{AK}$ & $\mathrm{pH}$ & $\mathrm{NO}_{3}^{-}$ & clay & sand \\
\hline Average (x0) & 1.29 & 16.25 & 0.82 & 10.09 & 59.96 & 6.45 & 5.43 & 19.43 & 18.01 \\
Slope (b) & -2.5 & -2.5 & -2.5 & -2.5 & -2.5 & -2.5 & -2.5 & -2.5 & 2.5 \\
Weighting value & 0.16 & 0.21 & 0.14 & 0.06 & 0.13 & 0.08 & 0.05 & 0.09 & 0.08 \\
\hline
\end{tabular}

2 


\section{Table 8(on next page)}

Paired $t$ test values for effect on soil quality index (SQI) between vegetation restoration type and cropland 
1 Table 8 Paired t test values for effect on soil quality index (SQI) between vegetation 2 restoration type and the control

\begin{tabular}{|c|c|c|c|c|}
\hline Set & $0-30 \mathrm{~cm}$ & $0-10 \mathrm{~cm}$ & $10-20 \mathrm{~cm}$ & $20-30 \mathrm{~cm}$ \\
\hline $\mathrm{NS}-\mathrm{CK} 1$ & ++ & + & ++ & + \\
\hline \multicolumn{5}{|l|}{$\mathrm{EF}-\mathrm{CK} 2$} \\
\hline $\mathrm{PF}-\mathrm{CK} 3$ & & & + & \\
\hline $\mathrm{ZF}-\mathrm{CK} 4$ & ++ & & & \\
\hline \multicolumn{5}{|l|}{$\mathrm{JC}-\mathrm{CK} 5$} \\
\hline TG - CK6 & ++ & & + & \\
\hline
\end{tabular}

